\title{
Os estados no Suas: uma análise da capacidade institucional dos governos estaduais na assistência social
}

\author{
André Luis Nogueira da Silva \\ Fundação Instituto Brasileiro de Geografia e Estatística (IBGE) \\ Natal / RN - Brasil \\ Universidade Federal do Rio Grande do Norte (UFRN) / Programa de Pós-Graduação em \\ Estudos Urbanos e Regionais \\ Natal / RN - Brasil
}

\begin{abstract}
O artigo esboça um diagnóstico da capacidade institucional dos estados brasileiros na assistência social a partir da análise de três aspectos: financeiro, administrativo e político. Trata-se de um comparativo dos 26 estados da federação e do Distrito Federal utilizando-se dados secundários da Pesquisa de Informações Básicas Estaduais do IBGE de 2012, do Sistema de Coleta de Dados Contábeis do Governo Federal (SISTN) e do Relatório de Informações Sociais do Ministério do Desenvolvimento Social e Combate à Fome de 2011. Os dados demonstram que é possível haver formas diferentes de atuação dos estados mesmo no interior de um sistema nacional. A heterogeneidade ocorre devido à discricionariedade conferida pelo desenho institucional do Suas ao ente estadual. Tal situação contribui para perpetuação das desigualdades regionais já existentes, impedindo, assim, a consolidação do estado de bem-estar brasileiro.
\end{abstract}

Palavras-chave: federalismo; descentralização; assistência social; capacidade institucional.

Los estados en Suas: un análisis de la capacidad institucional de los gobiernos estatales en asistencia social

El artículo esboza un diagnóstico de la capacidad institucional de los estados brasileños en la asistencia social a partir del análisis de tres aspectos: financiero, administrativo y político. Esta es una comparación de los 26 estados de la Federación y el Distrito Federal a partir de datos secundarios de la Pesquisa de Informações Básicas Estaduais do IBGE de 2012, el Sistema de Coleta de Dados Contábeis do Governo Federal (SISTN) y el Relatório de Informações Sociais do Ministério do Desenvolvimento Social e Com-

DOI: http://dx.doi.org/10.1590/0034-7612139292

Artigo recebido em 15 ago. 2014 e aceito em 30 abr. 2015.

(c) (1)

Agradeço o apoio dispensado pelo IBGE e os valiosos comentários da professora Sandra Cristina Gomes. Vale salientar que erros e omissões são de única responsabilidade deste autor. 
bate à Fome de 2011. Los datos muestran que puede haber diferentes formas de acción de los estados, incluso dentro de un sistema nacional. La heterogeneidad se debe a la facultad discrecional conferida por el diseño institucional del Suas a los estados. Esta situación contribuye a la perpetuación de las desigualdades regionales existentes, evitando así la consolidación del estado de bienestar brasileño.

Palabras Clave: federalismo; descentralización; asistencia social; capacidad institucional.

The states in Suas: an analysis of the institutional capacity of state governments in social assistance The article outlines a diagnosis of the institutional capacity of Brazilian states in the social assistance from the analysis of three aspects: financial, administrative and political. This is a comparison of the 26 states of the federation and the Distrito Federal using secondary data from the Pesquisa de Informações Básicas Estaduais do IBGE from 2012, from the Sistema de Coleta de Dados Contábeis from Federal Government (SISTN) and from the Relatório de Informações Sociais do Ministério do Desenvolvimento Social e Combate à Fome from 2011. The data show that there may be different ways of states of performance even within a national system. The heterogeneity occur because to discretion conferred by the institutional design of Suas the state one. This situation contributes to the perpetuation of existing regional inequalities, precluding the consolidation of the Brazilian welfare state.

KEYWORDS: federalism; decentralization; social assistance; institutional capacity.

\section{Introdução}

Em contextos federativos a coexistência de múltiplos centros de poder exige a acomodação de interesses territoriais nas decisões governamentais. Isto porque as unidades federativas possuem, além de prerrogativas de autogoverno (self-rule), poder decisório na esfera nacional (shared-rule) (Elazar, 1995). Nessa perspectiva, federações teriam maior dificuldade de implementar políticas sociais universais, atuando como empecilho à estruturação de um estado de bem-estar.

O presente trabalho adota a concepção de Draibe (1993, 2007), para quem o estado de bem-estar seria composto por três elementos básicos: a prestação de serviços sociais pelo Estado; uma forma de relação entre Estado e mercado, que faz o primeiro atuar na resolução de problemas provocados pelo segundo; e a garantia de uma renda temporária ou permanente que resguarde os cidadãos de certos riscos sociais, como velhice, desemprego etc. Admite, ainda, que "os sistemas de proteção social constituem em países de desenvolvimento principal instrumento de compensação ou reequilíbrio, já que (...) viabiliza o trânsito e a incorporação das massas rurais na vida urbana" (Draibe, 2007:44).

No Brasil, a assistência social aparece como um dos pilares do sistema de proteção social. Esta apenas ganha contornos de direito social com a Constituição de 1988. Apesar da regulamentação dos princípios e diretrizes constitucionais advirem em 1993, com a Lei Orgânica de Assistência Social, foi com a criação do Sistema Único de Assistência Social (Suas), em 2005, que se definiu forma e conteúdo dos serviços socioassistenciais no país. Mimetizando a experiência descentralizadora do Sistema Único de Saúde (SUS), o Suas também seguiu a lógica municipalista, imputando aos governos intermediários uma função complementar e 
residual, a saber: o cofinanciamento e o apoio técnico junto aos municípios e o acompanhamento e a avaliação das ações locais.

Corroborando as premissas que apontam para influência do formato estatal na produção de políticas públicas (Pierson, 1995; Obinger, Leibfried e Castles, 2005), o federalismo brasileiro exigiu uma ação deliberada do governo central na condução do processo de descentralização das políticas sociais. Instrumentalizada a partir de sistemas nacionais de provisão de serviços públicos, a descentralização apenas conseguiu efetivar-se com estratégias bemsucedidas de indução por parte do governo federal (Arretche, 1999).

Para alguns autores, a constituição de sistemas nacionais não só contribuiria com a descentralização de atribuições, mas também fortaleceria a capacidade institucional dos entes subnacionais no contexto federativo (Franzese e Abrucio, 2013). Esses estudos possuem como locus investigativo os governos locais, devido ao caráter essencialmente municipalista da descentralização no Brasil. No entanto, o caráter cooperativo do federalismo vincula a efetividade das políticas sociais ao cumprimento das atribuições institucionais de todos os entes federados. Os estados, nesse sentido, possuem importante papel na consolidação do estado de bem-estar brasileiro.

Argumenta-se, aqui, que a adoção do Suas pouco contribuiu com o fortalecimento institucional dos governos estaduais. O que contraria a proposição que indica efeitos positivos da criação de sistemas nacionais (descentralização) nos entes subnacionais (Oates, 1999; Tiebout, 1956). Para tanto, o estudo esboçará um diagnóstico da capacidade institucional dos estados brasileiros na assistência social a partir da análise de três aspectos: financeiro, administrativo e político. Trata-se de um comparativo dos 26 estados da federação e do Distrito Federal utilizando-se dados secundários da Pesquisa de Informações Básicas Estaduais do IBGE de 2012, do Sistema de Coleta de Dados Contábeis do Governo Federal (SISTN) e do Relatório de Informações Sociais do Ministério do Desenvolvimento Social e Combate à Fome de 2011.

O texto desenvolve, inicialmente, uma breve discussão teórico-conceitual sobre a relação entre federalismo e estado de bem-estar social, enfatizando o caso brasileiro. Aborda-se, em seguida, o processo de descentralização das políticas sociais que, no Brasil, assumiu um caráter de municipalização. Antes de adentrar a análise do desenho institucional da assistência social e dos dados financeiros, políticos e administrativos, conceitua-se capacidade institucional, como forma de justificar a escolha das dimensões analisadas na pesquisa. Por fim, são postas algumas considerações à guisa de conclusão.

\section{A relação entre estado de bem-estar e federalismo}

A formatação federativa ou unitária de um Estado nacional advém do modo de repartição da sua autoridade política. Em federações, os governos são divididos verticalmente em diferentes níveis, de modo que a população de um território se submete a mais de uma autoridade política (Levi, 2010). Desta feita, as esferas de governo são independentes e soberanas, 
pois têm autonomia política — seus governantes são eleitos — e fiscal para implementar suas próprias ações.

Recorrendo à literatura internacional, Franzese e Abrucio (2013) tratam sobre o impacto do desenho federativo nas políticas públicas a partir da análise dos modelos competitivo e cooperativo. O primeiro seria caracterizado pela distribuição de atribuições a partir das áreas de atuação governamental. O segundo, por sua vez, prevê a atuação conjunta numa mesma área de política pública, repartindo, apenas, competências funcionais para cada nível de governo.

$\mathrm{O}$ arranjo competitivo concede poder tributário às esferas de governo, o que contribui para a ocorrência de disputa entre eles. Por esse motivo, argumenta-se que esse modelo pode gerar um problema de ação coletiva. Pode implicar, além disso, a redução de investimentos na área social, que ocorreria para evitar a atração de novos beneficiários (free riders). ${ }^{1}$

No formato cooperativo não haveria competição tributária. No entanto, a necessidade de atuação conjunta elevaria o número de veto players, ${ }^{2}$ o que maximizaria o risco da paralisia decisória. Quando não, ampliaria a rigidez das políticas públicas, que passariam a ter de se moldar a diferentes interesses. Tal situação seria um empecilho a mudanças mais profundas e dificultaria a responsividade às demandas da população. Nesse sentido, as ações governamentais seriam puramente incrementais.

Os autores apontam problemas nessa classificação dual, citando o próprio caso brasileiro.

Observando essas duas condições, percebe-se que a Constituição não definiu claramente um modelo de federalismo competitivo ou cooperativo para o país. Ao desenhar uma federação descentralizada, o texto segue a direção de um modelo mais propício à competição. Porém, ao prever a responsabilidade compartilhada de atribuições em diversas áreas de políticas públicas, a Carta aponta no sentido de uma necessária cooperação entre os entes federativos. (Franzese e Abrucio, 2013:364)

O desenho federativo brasileiro, assim, seria híbrido, vez que composto por características do modelo competitivo, como é o caso da descentralização fiscal, e por elementos da forma cooperativa, com a previsão de atuação conjunta em determinadas áreas de atuação estatal. Portanto, tal categorização mostra-se insuficiente para explicar a relação entre federalismo e ação governamental.

\footnotetext{
${ }^{1}$ Para Olson (1999), mesmo que os membros de um grupo saibam que agir coletivamente favorece a consecução de objetivos comuns, esse conhecimento não é suficiente para fazê-los atuar. Isto porque muitos indivíduos não querem assumir os custos da ação, esperando pela atuação do "outro". Desse modo, os indivíduos “inertes" (free-riders) receberiam os benefícios sem assumir os custos da ação. Analogamente, em contextos de federalismo competitivo a ação coletiva das unidades federadas seria ainda mais prejudicada, tendo em vista a restrita existência de interesses comuns. ${ }^{2}$ Segundo Tsebelis (1997:2), "veto player é um ator individual ou coletivo cuja concordância é necessária para que se tome uma decisão política". Neste sentido, um grande número de veto players tende a tornar mais moroso e complexo o processo de tomada de decisão.
} 
Pierson (1995) afirma que o principal impacto do federalismo nas políticas estatais está na criação de unidades autônomas, capazes de atuar por conta própria e de influenciar as ações do governo central. Para ele, isso complexifica os desenhos de políticas públicas, que precisam acomodar diferentes interesses (regionais, locais, partidários etc.) em suas configurações. A importância de seus estudos está na desvinculação desses problemas ao modelo competitivo ou cooperativo. Acredita, assim, na coexistência das duas características numa mesma federação, como é o exemplo brasileiro.

Obinger, Leibfried e Castles (2005) colocam que os efeitos da relação entre estados de bem-estar e o federalismo divergem conforme a ordem no tempo em que se desenvolveram. Para eles, a facilidade ou dificuldade de implementação de políticas sociais e, assim, da estruturação de um estado de bem-estar depende da existência prévia de um federalismo democrático. Desta feita, quando o Welfare State começa a se estruturar em meio a um federalismo centralizado e autoritário, as políticas sociais se desenvolvem mais rapidamente. $\mathrm{Na}$ mesma linha, em contextos de federalismo democrático o estado de bem-estar teria maiores dificuldades para se estruturar.

Franzese e Abrúcio (2013:371-372) tentam adequar o modelo analítico ao caso brasileiro:

o federalismo [no Brasil] não teria sido um obstáculo à nacionalização de políticas sociais, uma vez que estas são prévias ao contexto federativo democrático. (...) Por outro lado, não se pode desconsiderar que a mesma Constituição também traz inovações na área de políticas públicas, institucionalizando uma agenda de políticas sociais com diretrizes de universalização e igualdade de acesso, típicas de um modelo de Estado de Bem-Estar Social e que não estavam presentes na trajetória prévia dessas políticas. Neste sentido, a Carta pode ser considerada como um marco não só no desenho federativo, mas também no desenho das políticas sociais, (...) uma situação semelhante àquela encontrada (...) em países nos quais o Estado de Bem-Estar Social se desenvolveu em um contexto federativo e democrático. (grifo nosso)

Por entenderem que o Welfare State apenas se desenvolveu no contexto pós-1988, devido à universalização das políticas sociais trazida como exigência constitucional, os autores admitem uma maior dificuldade na implementação de políticas sociais no país.

Outra proposição de Obinger, Leibfried e Castles (2005) é de suma importância para a compreensão da relação entre federalismo e políticas públicas: a existência de uma reciprocidade causal. A ideia é que os contextos federativos não só afetam as políticas sociais, mas também são por ela influenciados. Analisando as políticas de saúde, educação e assistência social no Brasil, Franzese e Abrúcio (2013) concluem que os processos de descentralização, promovidos a partir da constituição de sistemas nacionais, fortaleceram o poder dos entes subnacionais, dificultando ações unilaterais por parte do governo central na alteração de desenhos de políticas sociais. Portanto, o desenvolvimento de sistemas nacionais de provisão de serviços públicos afetaria as formas de relacionamento intergovernamental, emoldurando um novo desenho federativo, mais afeito à cooperação. Para melhor compreendermos o desenho institucional das políticas sociais e o papel das unidades subnacionais no federalismo brasilei- 
ro faz-se necessário conhecer um pouco sobre os processos de descentralização implementados no Brasil após a Carta de 1988.

\section{Descentralização e políticas sociais no Brasil}

Como já dito, o contexto histórico de um país é de suma importância para compreensão do desenvolvimento/desmantelamento do estado de bem-estar. Neste sentido, a Ditadura Militar (1964-85) deixou marcas no sistema político brasileiro, vez que influenciou as mudanças instituídas pela Constituição de 1988. No período autoritário, as relações intergovernamentais do país foram caracterizadas pela extrema centralização decisória, exemplificada pela destituição de governadores e prefeitos de seus cargos e pela concentração de poder tributário no governo central. A ausência de autonomia dos entes subnacionais, assim, dificultava até mesmo a concepção federativa do Estado brasileiro.

O centralismo autoritário dos militares, atomizado pelos péssimos resultados econômicos e pela dilaceração das condições sociais, passou a ser sinônimo de ineficiência. Formulou-se, assim, um consenso de que a descentralização das políticas públicas geraria mais democracia. Para a esquerda latino-americana, ela seria um meio para superar os problemas do Estado, pois facilitaria o controle social, reduzindo o clientelismo. Para os liberais, ela dotaria a sociedade civil com mais liberdade, gerando maior capacidade de iniciativa (Arretche, 1996).

Arretche questiona tal concepção ao comprovar lógica e empiricamente que o aprofundamento do ideal democrático independe da escala ou âmbito do processo decisório. Segundo ela, "A proximidade não é (...) condição suficiente para evitar que determinadas necessidades dos cidadãos sejam atendidas segundo padrões clientelísticos" (Arretche, 1996:18). A democracia, na verdade, apenas pode ser satisfeita com a existência de instituições que garantam seus valores e princípios. Assim, a descentralização das ações governamentais pode até ser importante, mas não é suficiente para garantia da democratização do processo decisório.

A autora refuta ainda a possibilidade de esvaziamento das funções do governo central como consequência da descentralização. Na verdade, o sucesso deste processo depende do fortalecimento da capacidade institucional e administrativa do governo central na coordenação e regulação de políticas nacionais.

Com a Constituição de 1988, estados e municípios passaram a assumir responsabilidades na gestão de políticas públicas. Devido ao novo contexto federativo, eles podiam atuar ou por iniciativa própria ou a partir da adesão a algum programa proposto por um nível mais alto de governo. Tal prerrogativa adveio da instituição de atribuições comuns estabelecida pelo ordenamento constitucional. Para Franzese e Abrúcio (2013:372), "O rol de competências constitucionais comuns favoreceu a indefinição de responsabilidades entre os entes federativos, enquanto as diretrizes constitucionais de descentralização e universalização de políticas sociais fortaleceram os municípios". 
Esse contexto permitiu tanto a inércia quanto a inovação por parte dos governos subnacionais. A inércia tinha como pano de fundo o "jogo de empurra"3 causado pela ampla quantidade de atribuições comuns. Já as inovações aconteceram, sobretudo, nos municípios, devido à ampliação de suas receitas advindas com a descentralização fiscal. O governo central, diante disso, assume importante papel: "de forte regulação das políticas nacionais, de correção das desigualdades regionais e de compensação das insuficiências locais" (Arretche, 1996:17).

Em análise sobre o desenvolvimento das políticas sociais no Brasil, Arretche (1999) confirma a função coordenativa e indutora do governo federal como elemento preponderante para o sucesso dos processos de descentralização. Segundo a autora, a adesão dos entes subnacionais a programas de descentralização de funções está condicionada a um cálculo feito pelos gestores quanto aos custos e benefícios de sua decisão. Neste sentido, a "ação política deliberada" do governo central, através de estratégias de indução, é essencial para eficácia do processo descentralizador. Assim, ao contrário do que se pensa,

atributos estruturais das unidades locais de governo, tais como a capacidade fiscal e administrativa e a cultura cívica local, têm um peso determinante para a descentralização. Mas, tais fatores não são determinantes em si. Seu peso e importância variam de acordo com requisitos institucionais postos pelas políticas a serem assumidas pelos governos locais, tais como o legado das políticas prévias, as regras constitucionais e a própria engenharia operacional de cada política social. (Arretche, 1999:112)

A ideia de que fatores estruturais das esferas subnacionais de governo não são elementos determinantes na eficácia da descentralização coloca o governo federal como mais importante ator no desenvolvimento do estado de bem-estar brasileiro. Nessa perspectiva, a constituição de sistemas nacionais de políticas públicas pelo governo central contribuiria para fortalecer o poder dos demais entes federados, favorecendo, inclusive, a ampliação da capacidade institucional de estados e municípios no contexto federativo (Franzese e Abrucio, 2013). Ou seja, o fortalecimento institucional dos governos subnacionais seria contingente à ação deliberada do governo central na criação de sistemas nacionais de políticas públicas.

Observa-se, assim, que a adoção de sistemas nacionais foi o instrumento utilizado pelo governo central para efetivação da descentralização no Brasil. Apesar da perspectiva sistêmica, em muitos casos, descentralização confundiu-se com municipalização. Isto porque a preocupação inicial do governo federal estava na expansão de serviços sociais, que seriam prestados diretamente pelos governos locais. Aos estados caberia uma função residual e/ou de complementariedade técnica e financeira aos municípios

Em análise sobre a descentralização promovida pelo Sistema Único de Saúde (SUS), Andrade e Castanheira (2011) identificam problemas quanto à participação dos estados na política de saúde. Segundo os autores:

\footnotetext{
${ }^{3}$ A existência de atribuições comuns permite que os entes federados responsabilizem o outro pela ausência de determinados serviços públicos.
} 
Se por um lado o processo de descentralização da gestão para os municípios favoreceu de forma concreta a capilarização dos serviços e ampliação do acesso à população, por outro, propiciou um afastamento do estado na regulação de sistemas regionais, reservando-lhe um papel abstrato. Ao mesmo tempo, a esfera federal passou a estabelecer uma relação mais direta com os municípios, numa combinação de centralização política e financeira com descentralização setorial, contribuindo com o enfraquecimento da capacidade política dos estados em formular políticas supramunicipais. (Andrade e Castanheira, 2011:982)

A função "abstrata" dos estados foi resultado de uma flexibilidade de atuação amparada pelos normativos do SUS. Tal flexibilidade é verificada também na descentralização da política educacional. Em estudo sobre a implementação do Fundef, ${ }^{4}$ Gomes (2009) identificou uma variação entre os estados na oferta de vagas do ensino fundamental pelos governos locais. Segundo ela, um dos fatores explicativos para a rápida municipalização da educação foi o papel indutor do nível intermediário de governo. Ou seja, estados que promoveram ações que incentivavam os municípios a aderirem ao Fundef avançaram mais rapidamente na municipalização da educação fundamental. É perceptível, portanto, uma flexibilidade de atuação dos estados na saúde e na educação, decorrente dos dispositivos normativos que regem os sistemas. Ademais, se o governo estadual possuiu uma função essencial no apoio à efetivação da municipalização, ao esgotar-se esse processo seu papel torna-se ainda mais "incerto".

\section{A governança nos governos subnacionais: como analisar capacidades institucionais?}

Mas como saber de fato se os processos de descentralização, sobretudo os instituídos sob o formato de sistemas nacionais, afetam a capacidade institucional dos entes subnacionais? Antes disso, o que envolve a dimensão institucional de uma esfera de governo, para que se analise sua efetividade no contexto federativo brasileiro?

É bastante vasta a produção acadêmica que se preocupou em compreender as reformas de descentralização e seus efeitos no bem-estar coletivo. Muitos desses trabalhos convergem no sentido da geração de efeitos positivos decorrentes do processo descentralizador. Uma vertente mais economicista identifica na descentralização fiscal um meio de assegurar a eficiência alocativa. Ou seja, a transferência de funções para os governos subnacionais seria condição suficiente para efetividade da ação estatal.

Oates (1999), por exemplo, enxerga que a competição gerada pela descentralização incita os governos locais a buscarem eficiência nos serviços ofertados e nos tributos cobrados.

\footnotetext{
${ }^{4}$ Fundo de Manutenção e Desenvolvimento do Ensino Fundamental e de Valorização do Magistério (Lei no 9.424/1996). Trata-se de um fundo de natureza contábil que vincula recursos estaduais e municipais para uso exclusivo na educação fundamental. Convém colocar que, conforme previsto pela própria Lei de Diretrizes e Bases da Educação (Lei $\mathrm{n}^{\circ}$ 9.394/1996), esse nível de ensino poderia ser ofertado por qualquer dos entes subnacionais.
} 
Na mesma direção, Tiebout (1956) argumenta que apenas no contexto local os cidadãos podem apresentar suas preferências..$^{5} \mathrm{O}$ problema desses estudos é que não consideram as diferenças existentes entre os entes subnacionais. Assim, "As well as reasons of substantive social justice, this State model would inevitably create inefficient and ineffective policies, given that localities would have different capacities (fiscal, administrative etc.) to respond to the 'preferences' of their citizens" (Gomes, 2010:110).

Outras linhas de análise avançam no sentido de considerar múltiplas dimensões da descentralização. Aspectos políticos, administrativos e financeiros seriam essenciais para compreensão do impacto da descentralização nos governos subnacionais. Schneider (2003), em estudo comparativo entre 68 países, identifica que a autonomia administrativa, mais que as outras dimensões, impacta positivamente a responsividade dos governos locais em relação às demandas de sua população. Ou seja, a capacidade administrativa, entendida como a autonomia para decidir sobre políticas e objetivos estatais, é fator determinante para compreensão da performance do governo.

Outros autores, no entanto, defendem a supremacia da dimensão política para compreensão da efetividade dos governos subnacionais. Treisman (2007) afirma não haver relação entre capacidade administrativa e autonomia decisória. Enquanto a primeira diria respeito às condições de execução de ações por parte de agentes locais - que poderiam ser vinculados ao governo central — , a segunda deveria ser tratada no âmbito da dimensão política. Assim, apenas existiria autonomia nos casos em que o governo possuísse autonomia exclusiva numa área de política pública.

Apesar do avanço das análises de Schneider e Treisman, no sentido de considerarem a importância de múltiplas dimensões da descentralização, ambas suscitam críticas, sobretudo quanto à metodologia utilizada em seus estudos. Tal problema advém da falta de uma definição conceitual unívoca sobre as dimensões da descentralização. Se para Schneider (2003) a capacidade de gastos compõe a dimensão administrativa, para Treisman (2007) a autonomia decisória refere-se ao aspecto político.

Segundo Gomes (2010:116),

there is no consensus as to the effects that different types and degrees of decentralization produce on the performance of subnational governments. Thus, if the studies in the area consider it necessary to distinguish between the dimensions of decentralization as an explanatory factor, then a first step in this direction would be to create a common conceptual reference.

\footnotetext{
${ }^{5} \mathrm{O}$ modelo concebido pelo autor admite a existência de diferentes "pacotes de serviços" e de tributos nas localidades, o que levaria os cidadãos a escolherem quais se adequariam à sua necessidade. Assim, a oferta de serviços públicos e os impostos instituídos seriam fatores explicativos para a mobilidade da população. Tal perspectiva é bastante criticada, vez que não apresenta indicadores que comprovem a sobreposição dos serviços públicos e da cobrança de impostos enquanto determinantes para migração.
} 
A autora vai mais além ao afirmar que talvez a preocupação dos estudos sobre descentralização não esteja na transferência de atribuições aos governos, mas sim na autonomia decisória dos entes federados. Assim sendo, para entender os efeitos da descentralização seria necessário verificar o nível de autonomia decisória dos governos subnacionais.

Outro viés de análise sobre os processos de descentralização é encontrado nos estudos do Banco Mundial (The World Bank, 1994). Baseados na perspectiva neoinstitucionalista, esses trabalhos consideram o desenho institucional das reformas de descentralização como fator decisivo nos resultados do governo. Admitem, dessa forma, a possibilidade de efeitos negativos decorrentes da transferência de funções. Entre os impactos negativos estaria o aumento das disparidades internas. Nesse caso, o problema poderia ser mitigado pela prevalência de transferências governamentais, com vistas a subsidiar governos com menos capacidades.

As reformas descentralizadoras, portanto, devem considerar a capacidade administrativa e fiscal dos governos subnacionais em seu desenho, bem como prever a existência de canais de participação e de accountability nos diversos níveis de governo. A conclusão a que se chega nesses trabalhos é de que regras institucionais podem gerar efeitos que variam conforme o contexto em que são adotadas.

Outra perspectiva analítica sobre o impacto descentralizador advoga pela importância da liderança política local e das regras da implementação da política como fatores determinantes no resultado dos governos subnacionais. As reformas de descentralização são vistas, assim, como oportunidades que, quando aproveitadas por empreendedores políticos, podem gerar efeitos benéficos para a população. Conforme posto por Grindle (2007), as lideranças locais precisam ter capacidade para produzir consensos em relação a reformas administrativas, bem como ser capazes de instituir canais de comunicação com a população.

Ao se debruçar sobre tais aportes analíticos, Gomes (2010) propõe uma análise empírica integrada, que considere os seguintes fatores: capacidade fiscal, política e administrativa; desenho institucional das políticas; e o papel da liderança política local. O estudo desses aspectos permitiria uma pesquisa mais acurada sobre os efeitos das reformas descentralizadoras.

\section{Metodologia}

O presente trabalho busca seguir o caminho da análise integrada proposto por Gomes (2010). Optou-se por deixar de fora a função da liderança política local, tendo em vista o viés qualitativo exigido para sua compreensão. Tal ausência não significa, no entanto, falta de importância para o entendimento da descentralização da assistência social. A liderança política estadual, na verdade, pode ser um dos principais determinantes para efetividade do Suas em alguns estados (Costa e Palotti, 2013). Acreditamos, por outro lado, que a análise das outras dimensões é suficiente para o que se pretende neste artigo.

No que se refere ao desenho institucional da assistência social, será feita uma análise de conteúdo dos principais normativos que regem essa política. A premissa é de que a engenharia institucional do Suas afeta a atuação dos governos subnacionais. 
Em seguida, utilizam-se indicadores fiscais, administrativos e políticos para mensurar a capacidade institucional dos 26 governos estaduais e do DF na assistência social. Isso servirá para verificarmos se a criação de sistemas nacionais de políticas públicas contribui no fortalecimento institucional das esferas de governo, no caso deste trabalho, nos governos estaduais. Os dados foram extraídos da Pesquisa de Informações Básicas Estaduais do IBGE de 2012, do Sistema de Coleta de Dados Contábeis do Governo Federal (SISTN) e do Relatório de Informações Sociais do Ministério do Desenvolvimento Social e Combate à Fome de 2011.

Com vistas a formatar um ranking da capacidade institucional dos estados, elaborouse um índice composto pelas três dimensões. Para tanto, definiu-se um indicador para cada dimensão analisada, distribuindo-o em quartis. A ideia foi de homogeneizar os indicadores, permitindo sua congregação em um escore, que nomeamos de Índice de Capacidade Institucional da Assistência Social (ICAS).

\section{0 recente desenvolvimento institucional da política de assistência social}

Como todas as políticas sociais no Brasil, a assistência social começa a trilhar novos caminhos com o novo ordenamento constitucional de 1988. Anteriormente, os serviços vinculados a essa área de política pública eram tidos menos como direitos sociais do que como obra de caridade. Prestados por organizações filantrópicas, iniciativas assistenciais mostravam-se caminho frutífero para práticas clientelistas e politiqueiras.

A importância da nova Carta foi, assim, a institucionalização dos serviços da assistência social como papel do Estado. O art. 203 traz os seguintes objetivos para o setor: a proteção à família, à maternidade, à infância, à adolescência e à velhice; o amparo às crianças e adolescentes carentes; a promoção da integração ao mercado de trabalho; a habilitação e reabilitação das pessoas portadoras de deficiência e a promoção de sua integração à vida comunitária; e a garantia de um salário mínimo mensal como benefício para idosos e deficientes que comprovem dele necessitar (Brasil, 1988).

Além disso, ao definir o caráter não contributivo da política, universaliza os serviços a todos que o demandarem. Coloca a descentralização política-administrativa e a participação popular nos três níveis de gestão como diretrizes da assistência social, atribuindo ao governo federal o papel de instituir normas gerais e aos estados e municípios a função de coordenar e executar as políticas.

A regulamentação desse dispositivo constitucional apenas veio em 1993, com a promulgação da Lei Orgânica da Assistência Social (Lei no 8.742/1993). Seu principal instituto é a condicionalidade de repasses financeiros do governo federal à existência de conselho, fundo e plano de assistência social. Tal exigência favoreceu a disseminação desses instrumentos de planejamento nos governos subnacionais, no mesmo período em que se constituiu o Conselho Nacional de Assistência Social e o Fundo Nacional de Assistência Social. Apesar disso, o normativo não resolvera um dos principais problemas do setor: "o financiamento da política 
e a distribuição de competências entre os entes federados permaneceram indefinidos" (Costa e Palotti, 2013:332).

Esse cenário de incertezas começa a se modificar em 2003. Naquele ano, a assistência social passa a ser tema prioritário na agenda governamental se desvinculando do Ministério da Previdência e ganhando uma pasta própria no organograma do Executivo Federal. O Ministério da Assistência Social, posteriormente, renomeado para Ministério do Desenvolvimento Social e Combate à Fome (MDS), começa a formular e implementar programas, visando garantir as exigências constitucionais. Absorvendo as deliberações da IV Conferência Nacional de Assistência Social, o MDS, em 2005, institui, por meio de uma Norma Operacional Básica (NOB), o Sistema Único da Assistência Social (SUAS).

O Suas inova ao definir as formas de atendimento da assistência social (proteção social básica e proteção social especial), bem como ao instituir três níveis de gestão da política: inicial, básico e pleno. Convém explicitar que essas modalidades de gestão existem apenas para adesão por parte dos municípios. As atribuições dos governos estaduais apenas aparecem com maior clareza com a Lei no $12.435 / 2011$, que altera a Loas. Com ela, a esfera estadual deve: destinar recursos aos municípios, visando sua participação no custeio dos serviços socioassistenciais; cofinanciar melhoria da gestão de programas e projetos da assistência social no âmbito local e regional; atender, junto com os municípios, ações emergenciais; estimular e apoiar técnica e financeiramente as associações e os consórcios municipais; prestar serviços assistenciais cujos custos ou ausência de demanda municipal justifiquem uma rede regional de serviços; e realizar o monitoramento da política de assistência social e assessorar os municípios para seu desenvolvimento (art. 13 da Loas).

Desta feita, no âmbito do Sistema Único da Assistência Social, os estados assumem principalmente prerrogativas de complementariedade técnica e financeira aos municípios. Atua na execução apenas em situações emergenciais ou de falta de demanda municipal pelos serviços assistenciais, devendo, no último caso, instituir redes regionalizadas de atendimento.

Investigando sobre a implementação do Suas em Minas Gerais, Costa e Palotti (2013) colocam que o governo estadual teve papel essencial no sucesso da habilitação dos municípios ao sistema. Segundo eles, o gestor estadual implementou ações paralelas de indução que contribuíram técnica e financeiramente para municipalização da assistência social, sobretudo, no âmbito da proteção social básica.

Diante disso, as atribuições instituídas para o nível intermediário de governo são elementos fundamentais para análise da capacidade institucional dos estados dentro do Suas. Fatores financeiros, administrativos e políticos devem ser suficientes para possibilitar o cumprimento de suas competências federativas.

\section{A capacidade institucional dos governos estaduais na assistência social}

Como já dito, estudos vêm indicando que a efetivação do estado de bem-estar social em contextos federativos depende da eficácia do governo central na constituição de sistemas na- 
cionais de políticas sociais. A adoção de estratégias bem-sucedidas de indução favoreceria a descentralização (Arretche, 1999, 2002, 2004), o que acabou por fortalecer institucionalmente os entes subnacionais (Franzese e Abrucio, 2013). Convém colocar que essas proposições surgiram a partir de pesquisas sobre os governos locais. Não há estudos que confirmem o real impacto da criação de sistemas nacionais no fortalecimento institucional do nível estadual. Nesse sentido, a avaliação da capacidade institucional dos governos estaduais na assistência social pode contribuir na confirmação, ou refutação, de tal proposição.

\subsection{Dimensão financeira}

Para análise da dimensão financeira, foram levantadas as despesas liquidadas na função assistência social em todos os estados brasileiros. Com isso, pode-se verificar a priorização da assistência social no orçamento dos governos estaduais. Formatou-se, assim, a tabela abaixo.

Tabela 1

Ranking dos estados com maior \% de despesas liquidadas na assistência social em 2011

\begin{tabular}{|c|c|c|c|c|c|}
\hline$\#$ & Região & UF & $\begin{array}{l}\text { Total de despesas } \\
\text { liquidadas em } 2011\end{array}$ & $\begin{array}{l}\text { Despesas liquidadas } \\
\text { na assistência social }\end{array}$ & $\begin{array}{l}\text { \% de despesas liquidadas na } \\
\text { assistência social em relação ao } \\
\text { total das despesas do estado }\end{array}$ \\
\hline 1 & Norte & PA & $R \$ 11.665 .083 .470,48$ & $R \$ 525.609 .281,36$ & $4,51 \%$ \\
\hline 2 & Norte & $\mathrm{AP}$ & $R \$ 2.656 .309 .355,89$ & $R \$ 86.597 .488,28$ & $3,26 \%$ \\
\hline 3 & Centro-Oeste & DF & $\mathrm{R} \$ 13.152 .624 .187,41$ & $R \$ 410.464 .229,47$ & $3,12 \%$ \\
\hline 4 & Norte & $\mathrm{RR}$ & $\mathrm{R} \$ 2.372 .660 .260,78$ & $R \$ 55.854 .238,03$ & $2,35 \%$ \\
\hline 5 & Nordeste & PB & $R \$ 5.927 .024 .431,79$ & $R \$ 138.980 .485,23$ & $2,34 \%$ \\
\hline 6 & Centro-Oeste & MS & $R \$ 9.185 .327 .840,58$ & $R \$ 208.626 .583,86$ & $2,27 \%$ \\
\hline 7 & Norte & $A C$ & $R \$ 3.608 .829 .367,96$ & $R \$ 79.670 .340,77$ & $2,21 \%$ \\
\hline 8 & Nordeste & RN & $R \$ 6.888 .982 .782,24$ & $R \$ 131.865 .888,83$ & $1,91 \%$ \\
\hline 9 & Nordeste & SE & $R \$ 5.517 .334 .114,25$ & $\mathrm{R} \$ 82.093 .328,48$ & $1,49 \%$ \\
\hline 10 & Nordeste & MA & $R \$ 9.084 .159 .972,41$ & $R \$ 122.595 .817,95$ & $1,35 \%$ \\
\hline 11 & Sudeste & ES & $\mathrm{R} \$ 12.269 .340 .988,21$ & $R \$ 152.662 .030,20$ & $1,24 \%$ \\
\hline 12 & Nordeste & BA & $\mathrm{R} \$ 26.874 .118 .104,48$ & $\mathrm{R} \$ 308.134 .918,03$ & $1,15 \%$ \\
\hline 13 & Nordeste & CE & $R \$ 16.303 .549 .803,42$ & $R \$ 186.065 .863,08$ & $1,14 \%$ \\
\hline 14 & Norte & AM & $R \$ 9.973 .952 .477,14$ & $R \$ 105.667 .465,25$ & $1,06 \%$ \\
\hline 15 & Centro-Oeste & $\mathrm{GO}$ & $\mathrm{R} \$ 13.201 .887 .721,54$ & $R \$ 120.929 .936,40$ & $0,92 \%$ \\
\hline 16 & Norte & TO & $R \$ 4.822 .414 .327,82$ & $R \$ 40.261 .806,82$ & $0,83 \%$ \\
\hline
\end{tabular}




\begin{tabular}{|cccccc|}
\hline$\#$ & Região & UF & $\begin{array}{c}\text { Total de despesas } \\
\text { liquidadas em 2011 }\end{array}$ & $\begin{array}{r}\text { Despesas liquidadas } \\
\text { na assistência social }\end{array}$ & $\begin{array}{c}\text { \% de despesas liquidadas na } \\
\text { assistência social em relação ao } \\
\text { total das despesas do estado }\end{array}$ \\
\hline 17 & Sul & PR & $\mathrm{R} \$ 23.497 .252 .665,95$ & $\mathrm{R} \$ 156.096 .496,94$ & $0,66 \%$ \\
18 & Nordeste & $\mathrm{AL}$ & $\mathrm{R} \$ 5.410 .479 .368,96$ & $\mathrm{R} \$ 34.405 .573,01$ & $0,64 \%$ \\
19 & Sul & $\mathrm{RS}$ & $\mathrm{R} \$ 35.629 .723 .308,16$ & $\mathrm{R} \$ 204.967 .131,45$ & $0,58 \%$ \\
20 & Sul & $\mathrm{SC}$ & $\mathrm{R} \$ 13.718 .745 .684,09$ & $\mathrm{R} \$ 71.208 .786,81$ & $0,52 \%$ \\
21 & Sudeste & $\mathrm{SP}$ & $\mathrm{R} \$ 159.949 .788 .187,88$ & $\mathrm{R} \$ 805.728 .964,51$ & $0,50 \%$ \\
22 & Sudeste & $\mathrm{RJ}$ & $\mathrm{R} \$ 54.105 .948 .774,95$ & $\mathrm{R} \$ 264.396 .147,37$ & $0,49 \%$ \\
23 & Sudeste & $\mathrm{MC}$ & $\mathrm{R} \$ 47.030 .664 .314,67$ & $\mathrm{R} \$ 193.738 .309,57$ & $0,41 \%$ \\
24 & Nordeste & $\mathrm{PE}$ & $\mathrm{R} \$ 19.188 .513 .810,62$ & $\mathrm{R} \$ 56.996 .515,26$ & $0,30 \%$ \\
25 & Nordeste & $\mathrm{Pl}$ & $\mathrm{R} \$ 5.686 .074 .602,75$ & $\mathrm{R} \$ 10.783 .453,44$ & $0,19 \%$ \\
26 & Norte & $\mathrm{RO}$ & $\mathrm{R} \$ 5.004 .230 .357,65$ & $\mathrm{R} \$ 7.104 .873,47$ & $0,14 \%$ \\
27 & Centro-Oeste & $\mathrm{MT}$ & $\mathrm{R} \$ 10.587 .500 .327,68$ & $\mathrm{R} \$ 7.408 .958,35$ & $0,07 \%$ \\
& & & $\mathrm{Média}$ Nacional & & $0,86 \%$ \\
\hline
\end{tabular}

Fonte: SISTN (2014). Elaborado pelo autor.

Os números apontam que apenas 15 estados efetivaram gastos acima da média obtida nacionalmente. Destaque para PA, AP e DF, que destinaram acima de 3\% do total de despesas liquidadas para a área de assistência social. O DF deve ser visto com ressalvas, vez que ele assume prerrogativas de estados e municípios. Portanto, assume a função de prestar diretamente os serviços assistenciais, o que amplia seu volume de gastos. Por outro lado, MT, RO, PI e PE investiram abaixo de $0,4 \%$ de suas despesas com a proteção social de seus habitantes. O que significa diminuta preocupação com essa política social.

Com base em dados do Censo Demográfico de 2010, o MDS estimou a quantidade de famílias de baixa renda nos estados. Para o órgão, famílias de baixa renda são aquelas que possuem renda familiar mensal per capita de até meio salário mínimo e as que possuem renda familiar mensal de até três salários mínimos. O reduzido nível de renda não representa fielmente a existência de vulnerabilidade social dentro de um território. No entanto, é fato que as famílias de baixa renda tendem a conviver com maiores riscos sociais. Portanto, este estudo entende-as como potenciais demandantes dos serviços da assistência social.

A tabela abaixo apresenta a relação das despesas estaduais na assistência social por estimativa de famílias de baixa renda: ${ }^{6}$

\footnotetext{
${ }^{6}$ A estimativa de famílias de baixa renda foi obtida a partir dos dados do Censo Demográfico de 2010. Já as despesas liquidadas referem-se a 2011. A diferença temporal dos dados não inviabiliza a relação das variáveis, tendo em vista que o planejamento orçamentário de 2011 leva em conta a situação do estado no ano anterior.
} 
Tabela 2

Estimativa de gastos estaduais da assistência social por família de baixa renda

\begin{tabular}{|c|c|c|c|c|}
\hline Região & UF & $\begin{array}{c}\text { Despesas liquidadas na } \\
\text { assistência social em } 2011\end{array}$ & $\begin{array}{l}\text { Estimativa de famílias com } \\
\text { baixa renda em } 2010\end{array}$ & $\begin{array}{l}\text { Despesa estadual por família de } \\
\text { baixa renda (despesas/famílias) }\end{array}$ \\
\hline Centro-Oeste & DF & $\mathrm{R} \$ 410.464 .229,47$ & 161.263 & $\mathrm{R} \$ 2.545,31$ \\
\hline Norte & $\mathrm{AP}$ & $R \$ 86.597 .488,28$ & 74.313 & $\mathrm{R} \$ 1.165,31$ \\
\hline Norte & $\mathrm{RR}$ & $R \$ 55.854 .238,03$ & 54.946 & $R \$ 1.016,53$ \\
\hline Centro-Oeste & MS & $R \$ 208.626 .583,86$ & 229.612 & $\mathrm{R} \$ 908,60$ \\
\hline Norte & $A C$ & $\mathrm{R} \$ 79.670 .340,77$ & 99.812 & $\mathrm{R} \$ 798,20$ \\
\hline Norte & PA & $R \$ 525.609 .281,36$ & 1.078 .680 & $\mathrm{R} \$ 487,27$ \\
\hline Sudeste & ES & $R \$ 152.662 .030,20$ & 343.540 & $\mathrm{R} \$ 444,38$ \\
\hline Nordeste & RN & $R \$ 131.865 .888,83$ & 451.964 & $\mathrm{R} \$ 291,76$ \\
\hline Sudeste & $\mathrm{SP}$ & $R \$ 805.728 .964,51$ & 2.794 .675 & $\mathrm{R} \$ 288,31$ \\
\hline Sul & RS & $\mathrm{R \$} 204.967 .131,45$ & 776.569 & $\mathrm{R} \$ 263,94$ \\
\hline Nordeste & SE & $\mathrm{R} \$ 82.093 .328,48$ & 317.401 & $R \$ 258,64$ \\
\hline Norte & AM & $R \$ 105.667 .465,25$ & 428.669 & $R \$ 246,50$ \\
\hline Nordeste & PB & $R \$ 138.980 .485,23$ & 600.136 & $\mathrm{R} \$ 231,58$ \\
\hline Sul & SC & $\mathrm{R} \$ 71.208 .786,81$ & 314.380 & $\mathrm{R} \$ 226,51$ \\
\hline Norte & TO & $\mathrm{R} \$ 40.261 .806,82$ & 185.698 & $R \$ 216,81$ \\
\hline Centro-Oeste & GO & $R \$ 120.929 .936,40$ & 560.474 & $\mathrm{R} \$ 215,76$ \\
\hline Sul & PR & $R \$ 156.096 .496,94$ & 793.523 & $R \$ 196,71$ \\
\hline Sudeste & RJ & $R \$ 264.396 .147,37$ & 1.430 .427 & $\mathrm{R} \$ 184,84$ \\
\hline Nordeste & $\mathrm{BA}$ & $\mathrm{R} \$ 308.134 .918,03$ & 2.205 .810 & $R \$ 139,69$ \\
\hline Nordeste & CE & $R \$ 186.065 .863,08$ & 1.340 .431 & $\mathrm{R} \$ 138,81$ \\
\hline Nordeste & MA & $R \$ 122.595 .817,95$ & 1.075 .986 & $\mathrm{R} \$ 113,94$ \\
\hline Sudeste & MG & $R \$ 193.738 .309,57$ & 1.918 .149 & $R \$ 101,00$ \\
\hline Nordeste & $A L$ & $R \$ 34.405 .573,01$ & 505.470 & $R \$ 68,07$ \\
\hline Nordeste & PE & $R \$ 56.996 .515,26$ & 1.374 .384 & $R \$ 41,47$ \\
\hline Norte & $\mathrm{RO}$ & $R \$ 7.104 .873,47$ & 173.867 & $R \$ 40,86$ \\
\hline Centro-Oeste & $\mathrm{MT}$ & $R \$ 7.408 .958,35$ & 295.477 & $R \$ 25,07$ \\
\hline Nordeste & $\mathrm{Pl}$ & $R \$ 10.783 .453,44$ & 509.299 & $\mathrm{R} \$ 21,17$ \\
\hline Total Nacional & & $R \$ 4.568 .914 .912,22$ & 20.094 .955 & $\mathrm{R} \$ 227,37$ \\
\hline
\end{tabular}

Fontes: SISTN (2014), MDS (2014). Elaborado pelo autor. 
A tabela 2 coloca DF, AP, RR, MS e AC como os estados com maior despesa por família de baixa renda do país. Ambos apresentaram gastos três vezes maiores do que a média nacional. O indicador ratifica a falta de priorização com assistência social de PE, RO, MT e PI, que registraram gastos por família de baixa renda que não ultrapassam 42 reais, o que equivale a cerca de $18 \%$ da média nacional. Devem-se destacar, ainda, as elevadas despesas por família de baixa renda do governo paranaense. Este, detentor de mais de 1 milhão de famílias vulneráveis, tem um gasto/família de baixa renda mais de duas vezes acima da média nacional, ficando na sexta posição no país.

As tabelas demonstram, sobretudo, a existência de uma elevada heterogeneidade na priorização dos gastos com assistência social, bem como no valor gasto por família de baixa renda. O que sugere a existência de autonomia estadual na definição de suas despesas, resultado, talvez, da falta de previsão normativa na vinculação de gastos na assistência social.

Como já colocado, a Loas traz como uma das principais atribuições dos estados o repasse financeiro aos municípios. Segue tabela com os municípios que fizeram repasse ou fundo a fundo ou por meio de convênios.

Tabela 3

Estados que efetivaram repasse financeiro aos municípios em 2011 e valor conforme a forma do repasse

\begin{tabular}{|cccc|}
\hline Região & UF & $\begin{array}{c}\text { Valor repassado aos } \\
\text { municípios fundo a fundo }\end{array}$ & $\begin{array}{c}\text { Valor repassado aos } \\
\text { municípios por convênio }\end{array}$ \\
\hline Norte & TO & - & $\mathrm{R} \$ 806.584,30$ \\
Nordeste & MA & $\mathrm{R} \$ 275.800,00$ & $\mathrm{R} \$ 91.725,00$ \\
Nordeste & CE & $\mathrm{R} \$ 5.437 .800,00$ & - \\
Nordeste & PB & - & $\mathrm{R} \$ 20.000,00$ \\
Nordeste & PE & - & $\mathrm{R} \$ 14.012 .647,34$ \\
Nordeste & AL & $\mathrm{R} \$ 2.568 .000,00$ & - \\
Sudeste & $\mathrm{R} \$ 14.954 .270,00$ & $\mathrm{R} \$ 13.651 .824,92$ \\
Sudeste & $\mathrm{RG} \$ 23.829 .680,00$ & $\mathrm{R} \$ 1.536 .770,02$ \\
Sudeste & $\mathrm{R} \$ 19.223 .590,00$ & - \\
Sudeste & $\mathrm{RS} \$ 150.587 .041,00$ & $\mathrm{R} \$ 7.593 .101,00$ \\
Sul & $\mathrm{RJ}$ & - & $\mathrm{R} \$ 6.994 .722,00$ \\
Sul & $\mathrm{SP}$ & $\mathrm{R} \$ 5.586 .900,00$ & - \\
Sul & PR & - & $\mathrm{R} \$ 7.192 .885,00$ \\
Centro-Oeste & $\mathrm{RC} \$ 9.917 .417,00$ & - \\
Centro-Oeste & $\mathrm{RS}$ & - & $\mathrm{R} \$ 2.208 .789,12$ \\
\hline
\end{tabular}

Fonte: IBGE (2012). Elaborada pelo autor. 
Como visto, apenas 15 estados efetivaram repasses financeiros aos municípios. O que indica falta de cumprimento das atribuições institucionais dos outros 12. Nesse quesito, os estados do Sudeste merecem destaque pelo pleno cumprimento da determinação legal de repasse aos governos locais, bem como pelas altas cifras dessas transferências. Esse cenário aponta para uma flexibilidade de atuação dos governos estaduais na assistência social, vez que apenas contribuem no financiamento de ações socioassistenciais nos municípios quando bem entendem. Indica também uma preponderância/amadurecimento institucional por parte dos estados do Sudeste.

\subsection{Dimensão administrativa}

$\mathrm{Na}$ análise da situação administrativa verificou-se a estrutura organizacional dos governos estaduais, o perfil de seu funcionalismo e a situação/existência de instrumentos de gestão inerentes à política de assistência social.

No que se refere à estrutura administrativa dos estados na assistência social, a Pesquisa de Informações Básicas Estaduais do IBGE (ESTADIC) registrou que, em 2011, apenas RO, AC, PA, AP, AL e SP possuíam órgão gestor exclusivo para área de assistência social. Ou seja, 20 estados juntamente com o DF não possuíam uma secretaria própria para o setor. Ademais, oito estados não executavam serviços socioassistenciais (TO, RN, AL, MG, ES, SP, PR e MT). Portanto, ou eles não possuíam localidades cujos custos ou ausência de demanda exijam prestações de serviços regionalizados (art. 13, inciso V da Loas), ou estavam descumprindo um mandamento legal.

Em relação aos instrumentos de planejamento, a Estadic verificou que todos os estados haviam instalado Comissão Intergestores Bipartite, o que significa a criação de um novo espaço de decisão intergovernamental. Por outro lado, apenas 11 estados possuíam Plano Estadual de Assistência Social aprovado, ferramenta primordial para orientar as ações dos governos a médio e longo prazo.

Outra competência definida pela Loas é o monitoramento da política de assistência social. A ESTADIC também investigou a existência de órgãos de monitoramento na estrutura organizacional dos governos estaduais. A pesquisa registrou que em 12 deles não havia um setor constituído ou existia de maneira informal. Tal situação dificulta a efetivação de ações avaliativas e de controle por parte do ente estadual, demonstrando, mais uma vez, a heterogeneidade institucional desse nível de governo.

Em se tratando do funcionalismo na área de assistência social dos governos estaduais, elaborou-se a tabela 4.

Os funcionários com nível superior foram destacados devido ao caráter especializado da prestação do serviço socioassistencial e às exigências de cooperação técnica junto ao município, outra atribuição imposta pela Loas aos estados. Na análise dos números destaca-se a quantidade de funcionários nos governos do Rio Grande do Sul (20) e do Rio Grande do Norte (25). Outros registros que impressionam são os números dos trabalhadores do Ceará (mais de 3 mil) e em Goiás (mais de 2 mil). Em se tratando de profissionais com nível superior, observa-se que quatro estados possuem menos de 50 funcionários com essa escolaridade. Por outro lado, DF, Goiás, Paraná e Ceará possuem todos mais de 500 trabalhadores com esse perfil. 
Tabela 4

Funcionalismo estadual na assistência social e relação dos funcionários de nível superior por estimativa de famílias com baixa renda

\begin{tabular}{|c|c|c|c|c|c|}
\hline Região & UF & $\begin{array}{c}\text { Total de funcionários } \\
\text { ativos }\end{array}$ & $\begin{array}{c}\text { Funcionários com } \\
\text { nível superior ou } \\
\text { pós-graduação }\end{array}$ & $\begin{array}{c}\text { Estimativa de } \\
\text { famílias com baixa } \\
\text { renda em } 2010\end{array}$ & $\begin{array}{c}\text { Relação Famílias } \\
\text { de baixa renda / } \\
\text { funcionários com } \\
\text { nível superior ou } \\
\text { pós-graduação }\end{array}$ \\
\hline Sul & RS & 20 & 15 & 776.569 & 51.771 \\
\hline Sudeste & MG & 78 & 43 & 1.918 .149 & 44.608 \\
\hline Nordeste & RN & 25 & 12 & 451.964 & 37.664 \\
\hline Nordeste & BA & 154 & 98 & 2.205 .810 & 22.508 \\
\hline Nordeste & PE & 180 & 123 & 1.374 .384 & 11.174 \\
\hline Nordeste & MA & 613 & 106 & 1.075 .986 & 10.151 \\
\hline Sul & SC & 73 & 40 & 314.380 & 7.860 \\
\hline Sudeste & RJ & 458 & 212 & 1.430 .427 & 6.747 \\
\hline Sudeste & SP & 1084 & 492 & 2.794 .675 & 5.680 \\
\hline Nordeste & $\mathrm{AL}$ & 249 & 95 & 505.470 & 5.321 \\
\hline Sudeste & ES & 177 & 82 & 343.540 & 4.190 \\
\hline Norte & PA & 881 & 306 & 1.078 .680 & 3.525 \\
\hline Norte & AM & 599 & 150 & 428.669 & 2.858 \\
\hline Nordeste & SE & 371 & 120 & 317.401 & 2.645 \\
\hline Centro-Oeste & MT & 445 & 124 & 295.477 & 2.383 \\
\hline Nordeste & CE & 3088 & 563 & 1.340 .431 & 2.381 \\
\hline Norte & $\mathrm{RO}$ & 385 & 74 & 173.867 & 2.350 \\
\hline Centro-Oeste & MS & 376 & 123 & 229.612 & 1.867 \\
\hline Nordeste & PB & 1331 & 354 & 600.136 & 1.695 \\
\hline Nordeste & $\mathrm{PI}$ & 1455 & 365 & 509.299 & 1.395 \\
\hline Sul & PR & 1898 & 594 & 793.523 & 1.336 \\
\hline Norte & $A C$ & 175 & 91 & 99.812 & 1.097 \\
\hline Norte & TO & 518 & 191 & 185.698 & 972 \\
\hline Norte & AP & 265 & 105 & 74.313 & 708 \\
\hline Centro-Oeste & $\mathrm{GO}$ & 2368 & 865 & 560.474 & 648 \\
\hline Norte & RR & 1179 & 196 & 54.946 & 280 \\
\hline Centro-Oeste & DF & 1938 & 943 & 161.263 & 171 \\
\hline \multicolumn{2}{|c|}{ Total Nacional } & 20.383 & 6.482 & 20.094 .955 & 3.100 \\
\hline
\end{tabular}

Fontes: IBGE (2012), MDS (2014). Elaborada pelo autor. 
Visando elaborar um indicador que pudesse mensurar a capacidade técnica dos estados, procedeu-se à relação: famílias de baixa renda por funcionário de nível superior. A ideia foi verificar quantas famílias dentro do estado um funcionário de nível superior deve atender. Mesmo considerando que os governos estaduais não necessitam ofertar serviços socioassistenciais de forma direta, pressupõe-se que as atribuições institucionais dos estados exigem um trabalho especializado, que se amplia proporcionalmente à quantidade de famílias socialmente vulneráveis.

Os dados registram que RS, MG, RN, BA, PE e MA possuem mais de 10 mil famílias potencialmente demandantes da assistência social para cada funcionário de nível superior. Enquanto em TO, AP, GO, RR e DF essa relação cai para menos de 1.000. Como nos outros indicadores analisados, o perfil do funcionalismo demonstra também uma elevada diversidade entre os estados. Apontam, ainda, para uma possível dificuldade no cumprimento de suas atribuições institucionais por parte dos estados com baixa capacidade técnica.

\subsection{Dimensão política}

A análise da dimensão política considerou a importância dos Conselhos de políticas públicas na democratização do processo decisório (Tatagiba, 2002). Desta feita, investigaram-se as principais características desse canal de participação popular, com vistas a verificar sua capacidade de influenciar as políticas da assistência social. Seguem algumas informações que permitem construir um diagnóstico de sua situação institucional.

Tabela 5

Principais características dos conselhos estaduais de assistência social em 2011 e índice de capacidade institucional

\begin{tabular}{|lccccccc|}
\hline & & $\begin{array}{c}(1) \\
\text { Existência de } \\
\text { recursos do } \\
\text { orçamento para } \\
\text { manutenção do } \\
\text { Conselho }\end{array}$ & $\begin{array}{c}\text { (2) } \\
\text { Conselho } \\
\text { fiscaliza }\end{array}$ & $\begin{array}{c}\text { Existência } \\
\text { de canal de } \\
\text { denúncias }\end{array}$ & $\begin{array}{c}\text { (4) } \\
\text { Conselho } \\
\text { delibera } \\
\text { sobre o } \\
\text { orçamento }\end{array}$ & $\begin{array}{c}\text { (5) } \\
\text { Conselho } \\
\text { participa da } \\
\text { elaboração } \\
\text { do PPA, LDO } \\
\text { e LOA }\end{array}$ & $\begin{array}{c}\text { Índice de } \\
\text { Capacidade } \\
\text { Institucional } \\
\text { (ICI) }\end{array}$ \\
\hline Nordeste & UF & 1,0 & 1,0 & 1,0 & 1,0 & 1,0 & 1 \\
Sudeste & MG & 1,0 & 1,0 & 1,0 & 1,0 & 1,0 & 1 \\
Centro-Oeste & MS & 1,0 & 1,0 & 1,0 & 1,0 & 1,0 & 1 \\
Centro-Oeste & MT & 1,0 & 1,0 & 1,0 & 1,0 & 1,0 & 1 \\
Centro-Oeste & GO & 1,0 & 1,0 & 1,0 & 1,0 & 1,0 & 1 \\
Centro-Oeste & DF & 1,0 & 1,0 & 1,0 & 1,0 & 1,0 & 1 \\
Sul & PR & 1,0 & 0,5 & 1,0 & 1,0 & 1,0 & 0,9 \\
Sul & SC & 1,0 & 0,5 & 1,0 & 1,0 & 1,0 & 0,9 \\
Norte & RO & 1,0 & 1,0 & 0,0 & 1,0 & 1,0 & 0,8 \\
\hline
\end{tabular}




\begin{tabular}{|c|c|c|c|c|c|c|c|}
\hline Região & UF & $\begin{array}{l}\quad(1) \\
\text { Existência de } \\
\text { recursos do } \\
\text { orçamento para } \\
\text { manutenção do } \\
\text { Conselho }\end{array}$ & $\begin{array}{c}\text { (2) } \\
\text { Conselho } \\
\text { fiscaliza }\end{array}$ & $\begin{array}{c}\text { (3) } \\
\text { Existência } \\
\text { de canal de } \\
\text { denúncias }\end{array}$ & $\begin{array}{c}(4) \\
\text { Conselho } \\
\text { delibera } \\
\text { sobre o } \\
\text { orçamento }\end{array}$ & $\begin{array}{c}(5) \\
\text { Conselho } \\
\text { participa da } \\
\text { elaboração } \\
\text { do PPA, LDO } \\
\text { e LOA }\end{array}$ & $\begin{array}{c}\text { Índice de } \\
\text { Capacidade } \\
\text { Institucional } \\
\text { (ICI) }\end{array}$ \\
\hline Norte & $\mathrm{PA}$ & 1,0 & 1,0 & 0,0 & 1,0 & 1,0 & 0,8 \\
\hline Sudeste & RJ & 1,0 & 1,0 & 1,0 & 1,0 & 0,0 & 0,8 \\
\hline Sul & RS & 1,0 & 1,0 & 1,0 & 1,0 & 0,0 & 0,8 \\
\hline Norte & AM & 1,0 & 0,5 & 1,0 & 1,0 & 0,0 & 0,7 \\
\hline Norte & $\mathrm{RR}$ & 1,0 & 0,5 & 0,0 & 1,0 & 1,0 & 0,7 \\
\hline Nordeste & RN & 1,0 & 0,5 & 0,0 & 1,0 & 1,0 & 0,7 \\
\hline Nordeste & BA & 1,0 & 1,0 & 0,0 & 1,0 & 1,0 & 0,7 \\
\hline Norte & $A C$ & 0,0 & 1,0 & 1,0 & 1,0 & 0,0 & 0,6 \\
\hline Norte & AP & 1,0 & 1,0 & 0,0 & 1,0 & 0,0 & 0,6 \\
\hline Norte & TO & 1,0 & 0,0 & 0,0 & 1,0 & 1,0 & 0,6 \\
\hline Nordeste & PB & 1,0 & 1,0 & 0,0 & 1,0 & 0,0 & 0,6 \\
\hline Nordeste & $\mathrm{PE}$ & 1,0 & 1,0 & 0,0 & 1,0 & 0,0 & 0,6 \\
\hline Sudeste & $\mathrm{SP}$ & 1,0 & 0,0 & 1,0 & 1,0 & 0,0 & 0,6 \\
\hline Nordeste & MA & 1,0 & 0,5 & 0,0 & 0,0 & 1,0 & 0,5 \\
\hline Nordeste & $\mathrm{PI}$ & 1,0 & 0,5 & 0,0 & 1,0 & 0,0 & 0,5 \\
\hline Nordeste & SE & 1,0 & 0,5 & 0,0 & 0,0 & 1,0 & 0,5 \\
\hline Nordeste & $\mathrm{AL}$ & 1,0 & 0,0 & 0,0 & 1,0 & 0,0 & 0,4 \\
\hline Sudeste & ES & 1,0 & 0,0 & 0,0 & 0,0 & 0,0 & 0,2 \\
\hline \multicolumn{7}{|c|}{ Média Nacional } & 0,7 \\
\hline
\end{tabular}

Fonte: IBGE (2012). Elaborado pelo autor.

Com vistas a criar uma medida que permitisse verificar o nível de influência dos Conselhos nas políticas de assistência social, foi elaborado um Índice de Capacidade Institucional (ICI). Sua construção seguiu a seguinte metodologia: as variáveis 1 , 3, 4 e 5 da tabela 5 receberam pontuação 1, quando obtiveram resposta "sim"; a variável 2 obteve pontuação de 0,5 para existência de fiscalização apenas na rede pública ou na rede conveniada do Suas e de 1 para existência de fiscalização em toda a rede do Suas. O somatório destes escores foi dividido por 5, chegando-se ao valor do ICI. Assim, quanto mais próximo o ICI de 1, maior influência dos Conselhos nas decisões estatais.

Os estados do CE, MG, MS, MT, GO e DF obtiveram escore 1, indicando um alto poder dos conselhos nas decisões da assistência social. Como visto, todos os estados do Centro-Oeste possuem Conselhos com maior capacidade institucional. Apesar disso, 11 estados tiveram ICIs abaixo da média nacional $(0,7)$. O destaque negativo ficou por conta do ES, cuja única característica que possui é a reserva de recursos orçamentários para manutenção destes fóruns participativos. 
Observando-se o comportamento dos ICIs, percebe-se uma grande diversidade nas características dos Conselhos estaduais de assistência social, o que implica uma disparidade no nível de permeabilidade dos governos para com a sociedade civil. Ou seja, a democratização do processo decisório por meio desses espaços acompanha os demais indicadores institucionais, apontando para uma elevada heterogeneidade institucional dos governos estaduais na assistência social.

\subsection{Análise multidimensional}

Visando verificar a capacidade institucional de cada estado na assistência social, congregaram-se as três dimensões em um índice composto. Como nas dimensões administrativa e financeira foram analisados vários indicadores, foi necessário definir o mais representativo para composição do índice. Desta feita, para dimensão financeira optou-se pelo percentual de despesas liquidadas na assistência social em relação ao total de despesas liquidadas do estado, e para dimensão administrativa foi escolhido o número de profissionais com nível superior ou pós-graduação.

O índice foi elaborado a partir da distribuição por quartis, em que cada parte recebeu as seguintes pontuações: 0,25; 0,50; 0,75 e 1. Feito isso para todas as dimensões, procedeu-se à média aritmética das três dimensões. $\mathrm{O}$ resultado pode ser encontrado na tabela seguinte.

Tabela 6

Ranking dos estados com maior capacidade institucional na assistência social

\begin{tabular}{|c|c|c|c|c|c|c|}
\hline \multirow[b]{2}{*}{$\#$} & \multirow[b]{2}{*}{ Região } & \multirow[b]{2}{*}{ UF } & \multicolumn{3}{|c|}{ Distribuição por quartis } & \multirow{2}{*}{$\begin{array}{l}\text { Índice de Capacidade } \\
\text { Institucional na } \\
\text { Assistência Social } \\
\text { (ICAS) }\end{array}$} \\
\hline & & & $\begin{array}{l}\text { Dimensão } \\
\text { financeira }\end{array}$ & $\begin{array}{c}\text { Dimensão } \\
\text { administrativa }\end{array}$ & $\begin{array}{c}\text { Dimensão } \\
\text { política }\end{array}$ & \\
\hline 1 & Centro-Oeste & DF & 1,00 & 1 & 1,00 & 1,00 \\
\hline 2 & Nordeste & CE & 0,75 & 1 & 1,00 & 0,92 \\
\hline 3 & Centro-Oeste & $\mathrm{GO}$ & 0,50 & 1 & 1,00 & 0,83 \\
\hline 4 & Centro-Oeste & MS & 1,00 & 0,5 & 1,00 & 0,83 \\
\hline 5 & Norte & PA & 1,00 & 0,75 & 0,75 & 0,83 \\
\hline 6 & Sul & PR & 0,50 & 1 & 0,75 & 0,75 \\
\hline 7 & Norte & $\mathrm{RR}$ & 1,00 & 0,75 & 0,50 & 0,75 \\
\hline 8 & Centro-Oeste & MT & 0,25 & 0,75 & 1,00 & 0,67 \\
\hline 9 & Nordeste & PB & 1,00 & 0,75 & 0,25 & 0,67 \\
\hline 10 & Norte & AM & 0,50 & 0,75 & 0,50 & 0,58 \\
\hline 11 & Norte & AP & 1,00 & 0,5 & 0,25 & 0,58 \\
\hline
\end{tabular}




\begin{tabular}{|c|c|c|c|c|c|c|}
\hline \multirow[b]{2}{*}{ \# } & \multirow[b]{2}{*}{ Região } & \multirow[b]{2}{*}{ UF } & \multicolumn{3}{|c|}{ Distribuição por quartis } & \multirow{2}{*}{$\begin{array}{l}\text { Índice de Capacidade } \\
\text { Institucional na } \\
\text { Assistência Social } \\
\text { (ICAS) }\end{array}$} \\
\hline & & & $\begin{array}{l}\text { Dimensão } \\
\text { financeira }\end{array}$ & $\begin{array}{c}\text { Dimensão } \\
\text { administrativa }\end{array}$ & $\begin{array}{c}\text { Dimensão } \\
\text { política }\end{array}$ & \\
\hline 12 & Nordeste & BA & 0,75 & 0,5 & 0,50 & 0,58 \\
\hline 13 & Sudeste & RJ & 0,25 & 0,75 & 0,75 & 0,58 \\
\hline 14 & Nordeste & MA & 0,75 & 0,5 & 0,25 & 0,50 \\
\hline 15 & Sudeste & MG & 0,25 & 0,25 & 1,00 & 0,50 \\
\hline 16 & Nordeste & $\mathrm{PI}$ & 0,25 & 1 & 0,25 & 0,50 \\
\hline 17 & Nordeste & $\mathrm{RN}$ & 0,75 & 0,25 & 0,50 & 0,50 \\
\hline 18 & Sul & RS & 0,50 & 0,25 & 0,75 & 0,50 \\
\hline 19 & Sul & SC & 0,50 & 0,25 & 0,75 & 0,50 \\
\hline 20 & Nordeste & SE & 0,75 & 0,5 & 0,25 & 0,50 \\
\hline 21 & Sudeste & $\mathrm{SP}$ & 0,25 & 1 & 0,25 & 0,50 \\
\hline 22 & Norte & TO & 0,50 & 0,75 & 0,25 & 0,50 \\
\hline 23 & Norte & $A C$ & 0,75 & 0,25 & 0,25 & 0,42 \\
\hline 24 & Nordeste & $\mathrm{AL}$ & 0,50 & 0,5 & 0,25 & 0,42 \\
\hline 25 & Sudeste & ES & 0,75 & 0,25 & 0,25 & 0,42 \\
\hline 26 & Norte & $\mathrm{RO}$ & 0,25 & 0,25 & 0,75 & 0,42 \\
\hline 27 & Nordeste & PE & 0,25 & 0,5 & 0,25 & 0,33 \\
\hline & & & Média Nacic & & & 0,60 \\
\hline
\end{tabular}

Fonte: Elaborado pelo autor.

Como esperado, observa-se uma elevada heterogeneidade na capacidade institucional dos estados no âmbito da assistência social. Os estados do Centro-Oeste apresentaram uma melhor situação, registrando Icas acima da média nacional. Convém lembrar, mais uma vez, que os altos scores adquiridos pelo DF decorrem da sua dupla função no federalismo brasileiro. Por outro lado, todos os estados do Sudeste, região que responde por cerca de 50\% do PIB nacional, registraram capacidade institucional na assistência social abaixo da média nacional $(0,60)$. Depreende-se, assim, que a capacidade institucional não possui relação com o nível de desenvolvimento econômico do estado.

Do mesmo modo, a quantidade de famílias de baixa renda - potenciais demandantes dos serviços socioassistenciais — também não aparece como variável determinante na capacidade institucional dos estados. Basta observar que os cinco estados com maior número de famílias vulneráveis (SP, BA, MG, RJ e PE) possuem Icas abaixo da média nacional. 
Os dados demonstram que é possível haver formas diferentes de atuação dos estados mesmo no interior de um sistema nacional. Tal heterogeneidade é possível devido à discricionariedade conferida pelo desenho institucional do Suas ao ente estadual. Assim sendo, as diferentes performances do nível intermediário de governo devem ser explicadas pelas escolhas ou estratégias de ação da liderança política estadual. Eleva-se, assim, a importância da realização de pesquisas de cunho qualitativo com vistas a entender o modo como essas decisões são tomadas, bem como os efeitos que elas podem gerar na efetivação da proteção social a indivíduos e famílias no Brasil.

\section{Considerações finais}

O feitio cooperativo do federalismo instituído em 1988 imprimiu inúmeros desafios para efetivação das políticas sociais no Brasil. A perspectiva de que a simples descentralização traria resultados positivos para a democracia e para a efetividade das políticas públicas esbarra na complexidade do contexto federativo brasileiro.

Os resultados atestam, neste sentido, a premissa de que a forma de organização estatal afeta as políticas públicas (Pierson, 1995). Por outro lado, a elevada heterogeneidade estadual no âmbito do Suas refuta a perspectiva de que a constituição de sistemas nacionais fortalece institucionalmente os governos subnacionais no contexto federativo (Franzese e Abrúcio, 2013; Oates, 1999; Tiebout, 1956).

A análise integrada, proposta por Gomes (2010), permitiu visualizarmos os efeitos da descentralização em suas múltiplas dimensões. No que se refere ao desenho institucional da política, a adoção de um sistema nacional como estratégia de descentralização da assistência social parece ter posto a reboque a importância do governo estadual. Ao impor aos estados prerrogativas meramente complementares e residuais, o governo federal, enquanto normatizador do SUAS, maximizou a autonomia daquele ente federado.

Na dimensão financeira, observou-se uma diversidade na priorização dos gastos com assistência social, bem como uma acentuada diferença no valor da despesa estadual por família de baixa renda. Uma possível explicação para tal situação é a falta de previsão legal de percentual de gastos com essa área de política pública no âmbito estadual. Ademais, a existência de 11 estados que não procederam a qualquer repasse financeiro aos municípios indica a falta de execução de uma de suas obrigações legais.

Em se tratando da dimensão administrativa, a falta de priorização dos serviços socioassistenciais se expressa na ausência de planos estaduais, de setores específicos para monitoramento da assistência social e na inexistência de secretaria exclusiva para tratamento do tema. O corpo técnico também apresentou bastante heterogeneidade entre os governos estaduais, podendo comportar 3 mil funcionários no Ceará ou meros 20 funcionários no Rio Grande do Sul. Além disso, a relação famílias de baixa renda por funcionário de nível superior também apresentou marcantes diferenças entre os estados. Tal achado reforça a ideia de que não há relação direta entre o tamanho da demanda potencial por serviços socioassistenciais, nem muito menos do volume de gastos, com a capacidade institucional dos estados. 
$\mathrm{Na}$ análise da dimensão política, as características investigadas e agregadas no Índice de Capacidade Institucional dos Conselhos comprovam a heterogeneidade da estrutura institucional dos governos estaduais na assistência social. Muitos deles apresentaram características que indicam fragilidade na capacidade de influenciar as decisões governamentais, sugerindo que o processo decisório ocorre exclusivamente no âmbito do executivo estadual.

A elaboração de um índice composto serviu para ratificar a diversidade da capacidade institucional dos estados. Verificaram-se, no entanto, bons escores por parte dos governos do Centro-Oeste e baixos níveis de capacidade institucional nos estados do Sudeste. Tal resultado pode ser reflexo de um dos aspectos não analisados neste trabalho e que deve ser alvo de outros estudos, a saber: a liderança política estadual.

Convém colocar, por fim, que a heterogeneidade da capacidade institucional dos estados no Suas contribui para perpetuação das desigualdades regionais já existentes, impedindo, assim, a consolidação do estado de bem-estar brasileiro.

\section{Referências}

ANDRADE, Marta C.; CASTANHEIRA, Elen R. Lodeiro. Cooperação e apoio técnico entre estado e municípios: a experiência do programa Articuladores da atenção básica em São Paulo. Saúde e Sociedade, São Paulo, v. 20, n. 4, p. 980-990, out./dez. 2011.

ARRETCHE, Marta. Federalismo e políticas sociais: problemas de coordenação e autonomia. São Paulo em Perspectiva, São Paulo, v. 18, n. 2, p. 17-26, abr. 2004.

ARRETCHE, Marta. O mito da descentralização: maior democratização e eficiência das políticas públicas? Revista Brasileira de Ciências Sociais, São Paulo, v. 11, n. 31, p. 44-66, jun. 1996.

ARRETCHE, Marta. Políticas sociais no Brasil: descentralização em um Estado federativo. Revista Brasileira de Ciências Sociais, São Paulo, v. 14, n. 40, p. 11-141, jun. 1999.

ARRETCHE, Marta. Relações federativas nas políticas sociais. Educação e Sociedade, Campinas, v. 23, n. 80, p. 25-48, set. 2002.

BRASIL. Congresso Nacional. Constituição Federal. Brasília, 1988.

CAIXA. Sistema de Coleta de Dados Contábeis (SISTN). Disponível em: <www.contaspublicas.caixa. gov.br/sistncon_internet/index.jsp>. Acesso em: 7 jul. 2014.

COSTA, Bruno L. D.; PALOTTI, Pedro L. M. Federalismo, descentralização e o novo arranjo institucional da política de assistência social: lidando com problemas de autonomia e coordenação. In: HOCHMAN, Gilberto; FARIA, Carlos A. P. (Org.). Federalismo e políticas públicas no Brasil. Rio de Janeiro: Fiocruz, 2013.

DRAIBE, Sonia. Estado de bem-estar, desenvolvimento econômico e cidadania: algumas lições da literatura contemporânea. In: HOCHMAN, Gilberto; ARRETCHE, Marta; MARQUES, Eduardo (Org.). Políticas públicas no Brasil. Rio de Janeiro: Fiocruz, 2007. 
DRAIBE, Sonia. Welfare State no Brasil: características e perspectivas. Caderno de Pesquisa Nepp/ Unicamp, n. 8, 1993. Disponível em: <www.nepp.unicamp.br/arquivos/caderno\%2008.pdf>. Acesso em: 4 jul. 2014.

ELAZAR, Daniel. From statism to federalism: a paradigm shift. Publius, Oxford, 1995.

FRANZESE, Cibele; ABRUCIO, Fernando Luiz. Efeitos recíprocos entre federalismo e políticas públicas no Brasil: os casos do sistema de saúde, de assistência social e de educação. In: HOCHMAN, Gilberto; FARIA, Carlos A. P. (Org.). Federalismo e políticas públicas no Brasil. Rio de Janeiro: Fiocruz, 2013. GOMES, Sandra. Políticas nacionais e implementação subnacional: uma revisão da descentralização pós-Fundef. Dados — Revista de Ciências Sociais, Rio de Janeiro, v. 52, n. 3, p. 659-690, 2009. GOMES, Sandra. The multi-faceted debate on decentralization and collective welfare. Brazilian Political Science Review, Rio de Janeiro, v. 4, n. 2, p. 103-128, 2010.

GRINDLE, Merilee S. Going local: decentralization, democratization, and the promise of good governance. Princeton: Princeton University Press, 2007.

IBGE. Pesquisa de Informações Básicas Estaduais (ESTADIC). 2012.

LEVI, Lucio. Federalismo. In: BOBBIO, Norberto; MATTEUCI, Nicolas; PASQUINO, Gianfranco. Dicionário de política. Brasília: Editora Universidade de Brasília, 2010.

MARQUES, Eduardo. Notas críticas à literatura sobre Estado, políticas estatais e atores políticos. Revista BIB, Rio de Janeiro, v. 43, n. sem. 1, p. 67-102, 1996.

MARSHALL, T. H. Cidadania, classe social e status. Rio de Janeiro: Zahar, 1967.

MDS. Relatório de Informações Sociais. Disponível em: < http://aplicacoes.mds.gov.br/sagi>. Acesso em: 12 jul. 2014.

OATES, Wallace E. An essay on fiscal federalism. Journal of Economic Literature, v. 37, n. 3, p. 1120-1149, 1999.

OBINGER, Herbert; LEIBFRIED, Stephan; CASTLES, Francis (Org.). Federalism and the Welfare State: New World and European experiences. Nova York: Cambridge University, 2005.

OLSON, Mancur. A lógica da ação coletiva. São Paulo: Edusp, 1999.

PIERSON, Paul. Fragmented Welfare States: federal institutions and development of social policy. Governance, v. 8, n. 4, p. 449-478, out. 1995.

SCHNEIDER, Aaron. Who gets what form whom? The impact of decentralization on tax capacity an pro-poor policy. IDS Working Paper 179. Brightin: Institute of Development Studies, 2003.

SILVA, André L. N. da; SOUZA, Damião E. de. Deliberação e controle social: um perfil dos conselhos estaduais de políticas públicas no nordeste brasileiro. Revista Eletrônica de Ciência Política, v. 4, n. 1-2, p. 80-100, 2013.

SISTN, Sistema de Coleta de dados contábeis do governo federal. Disponível em: <www.contaspublicas.caixa.gov.br/sistncon_internet/index.jsp>. Acesso em: 7 jul. 2014. 
SOUZA, Celina. Estado da arte da pesquisa em políticas públicas. In: HOCHMAN, Gilberto; ARRETCHE, Marta; MARQUES, Eduardo. Políticas públicas no Brasil. Rio de Janeiro: Fiocruz, 2007.

TATAGIBA, Luciana. Os conselhos gestores e a democratização das políticas públicas no Brasil. In: DAGNINO, Evelina (Org.). Sociedade civil e espaços públicos no Brasil. São Paulo: Paz e Terra, 2002.

THE WORLD BANK. World development report: infrastructure or development. Oxford University Press, 1994.

TIEBOUT, Charles. M. A pure theory of local expenditures. The Journal of Political Economy, v. 64, n. 5, p. 416-424, 1956.

TREISMAN, Daniel. The architecture of government: rethinking political decentralization. Nova York: Cambridge University Press, 2007.

TSEBELIS, George. Processo decisório em sistemas políticos: veto players no presidencialismo, parlamentarismo, multicameralismo e pluripartidarismo. Revista Brasileira de Ciências Sociais, São Paulo, v. 12, n. 34, jun. 1997.

André Luis Nogueira da Silva é mestre em estudos urbanos e regionais e analista de planejamento, gestão e infraestrutura da Fundação Instituto Brasileiro de Geografia e Estatística (IBGE). E-mail: andre.n.silva@ibge.gov.br. 